\title{
Wind Power Buildings Integration
}

\author{
Mladen Bošnjaković \\ The Technical Department, University of Applied Science of Slavonski Brod, Slavonski Brod 35000, Croatia
}

Received: January 30, 2013 / Accepted: March 1, 2013 / Published: April 25, 2013.

\begin{abstract}
The paper analyzes different turbine design suitable for the urban environment. The author discusses various options for setting up wind turbines in relation to the building. In order to gain insight into the real indicators, considered are actual examples of wind turbines mounted on buildings, sports facilities, roads, etc. However, these turbines have relatively low efficiency and a long payback period, and the problem may be the noise they produce. Therefore, the wind turbines installed in buildings are still more a matter of prestige of individual investors and architects than profitable investment.
\end{abstract}

Key words: Wind turbines, buildings.

\section{Introduction}

At the present time, the debates and discussion are being held about viability of wind. Experts have divided opinions about it and only about which they agree, is that wind turbines are cost effective and efficient if they are placed on high poles, or integrated with a facility in combination with any renewable energy source.

Wind speed increases with height so engineers came to the idea of installing wind turbines on top of buildings. Thus, the turbines can be set as independent objects on buildings and increase the usage of wind currents caused by the height. The second case is the integration of wind turbine in the construction of buildings (e.g., alongside a buildings), where the building itself mounts wind turbines. The third option is the installation of wind turbines positioned between two high buildings. In this case the buildings can speed up the wind velocity at the position of the wind turbine and/or create high turbulence levels. Wind turbines located at the high wind speed zones in buildings are called Building Augmented Wind Turbines (BAWT) because the wind turbine makes

\footnotetext{
Corresponding author: Mladen Bošnjaković, senior lecturer, M.Sc., research fields: renewable energy, programming of $\mathrm{CNC}$ machines. E-mail: mladen.bosnjakovic@vusb.hr.
}

use of the building as a concentrator of the wind. The concentrator effect will only be present for small wind turbine dimensions compared to the building dimension. This limits BAWT dimensions up to $20 \%$ of the characteristic building dimension.

By installing wind turbines in buildings, we produce energy where it is needed, and there is no loss of transmission. Turbines can meet about $15 \%$ of total energy demand of the building [1], everything else must be provided through other sources.

The paper is organized as follows: Section 2 is describing wind turbine design suitable for urban environment; section 3 is describing possible location of wind turbine on the building and section 4 gives examples of wind turbines integrated in buildings and possible problems connected with it; section 5 gives conclusions.

\section{Suitable Wind Turbine Designs}

The aerodynamic efficiency of a wind turbine depends upon other things on the way the wind energy is converted (lift or drag type wind turbine). A high aerodynamic efficiency (up to the Betz limit of 59\%) can be achieved for lift driven wind turbines. These wind turbines used airfoils in order to generate their driving force/lift and have a low material usage (Fig. 1). In contrast to them the drag driven wind turbines 


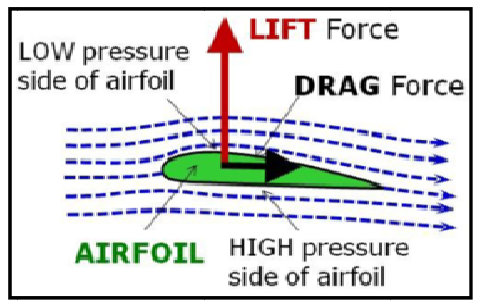

Fig. 1 Lift based wind turbine concept.

achieve lower aerodynamic efficiencies (up to about $15 \%)$ and have higher material usage. So the lift driven wind turbine is preferable for the BAWT largely for economic reasons.

There is several lift driven wind turbines that are possible candidates for the building.

Depending on orientation of the axes of rotation, wind turbines can have vertical (VAWT) or horizontal (HAWT) blades. There is some debate over whether HAWT or VAWT are most suitable for urban environment and which is best for building mounting. In the built environment where the wind flow is frequently turbulent, VAWT have the advantage of not needing to be directed into wind. Also, VAWT create fewer vibrations and make less noise. On the other hand HAWT are more efficient in terms of conversion of wind energy to electricity and more economic. Some calculations suggested that a building with an integrated HAWT could produce at least a $25 \%$ increase in annual energy yield in a typical urban setting over a freely yawing stand-alone turbine. Because of that both types of turbines are implementing in buildings. Other requirements for the design of urban wind turbines are

- Good performance in complex winds;

- Safe operation in the urban environment;

- Low noise level;

- Simple, rugged design;

- Minimised maintenance;

- Aesthetic appearance.

\section{Positioning of the Turbine}

\subsection{Locating between Diffuser Shaped Buildings}

In this case, buildings are positioned in such a way that they act as a diffuser for the wind turbine. Many tests were carried out on horizontal axes wind turbines in ring shaped diffusers. This combination results in a high aerodynamic efficiency compared to other possibilities. The diffuser needs to be long in order to generate an appreciable gain in aerodynamic efficiency. The common shape of the diffuser augmented wind turbine is not very suitable for the built environment. Because of that a combination of "diffuser" and "duct" is often applied.

\subsection{Locating in Building Facades}

Several designers have created building integrated wind turbines that fuses magnificent sculpture-like facades to augment wind flows onto turbines and generate more energy than is traditionally possible. Simultaneously, these artistic wind generating facades overcome some of the traditional problems with this type of dynamic facade, like noise and vibration.

Many of these building integrated wind energy systems use the concept of Wind Assisted Rotor Platform (WARP). These consist of small wind turbines mounted to the exterior of an aerodynamically shaped building. The saddle ridge shaped modules swirl around the building to channel and amplify the flows of wind (Fig. 2).

The disadvantage of alongside location is evidently that the performance will be strongly dependent upon the direction of the wind.

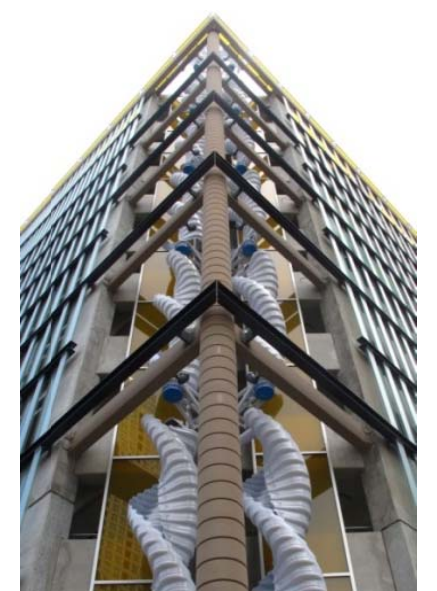

Fig. 2 Wind turbines integrated into a Chicago parking (via Flickr). 


\subsection{Locating on the Building Rooftop}

For locating on the roof, it has to be kept in mind that the flow separates at the leading roof edge and has an angle of about 45 degrees to the horizontal roof. For a Darrieus turbine, this effect will be less important. For common tip speeds, the blades will experience an almost horizontal flow. On a HAWT, the tilt will have a larger influence. The airfoils will stall, the aerodynamic efficiency will decrease and the rotor load will be non-uniform. So the Darrieus turbine seems preferable for locating on the roof of buildings.

\section{Examples of Wind Turbines Integrated in Buildings}

Since ancient times, man used wind energy through devices integrated on the building. At first, the public and the profession were very skeptical about the idea of installing wind turbines on buildings, primarily looking at the profitability of investment and possible negative consequences in the event of an accident. But as time progresses and the prices of fossil fuels rise, investors think about building integrated wind turbines $\left(\mathrm{BUWT}^{1}\right)$. So, we are witnessing the first buildings that have their own supply of electricity from wind turbines. First among them is the Bahrain World Trade Center located in Bahrain (Figs. 3-4).

On this building, it is possible to analyze all the arguments for and against the wind turbine integrated into the building.

In addition to low efficiency and a long payback time,

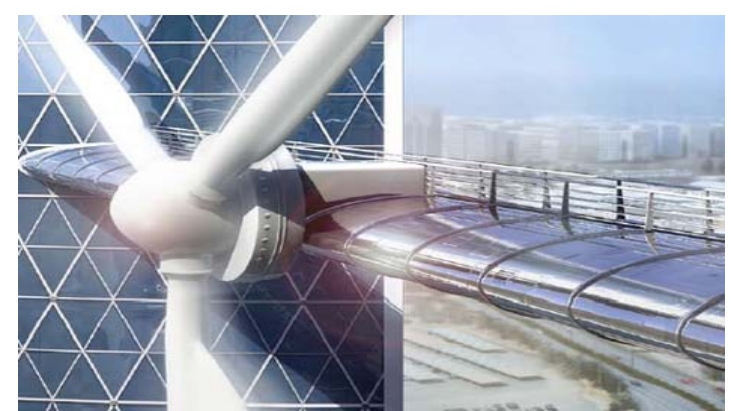

Fig. 3 Detail of Bahrain World Trade Center.

${ }^{1}$ BUWT_-Building-mounted Urban Wind Turbines.

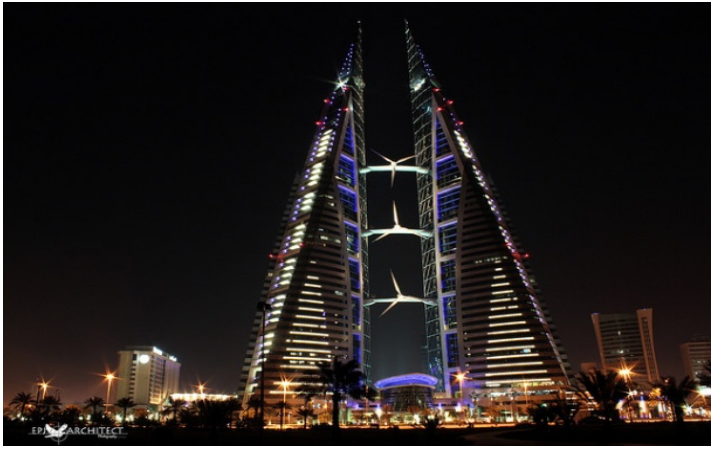

Fig. 4 Bahrain World Trade Center.

the problem with the wind generators is the noise that turbines make [2]. Regardless of the type of material from which the blades and the shaft bearing are made the wind flow creates noise that can be uncomfortable no matter of the frequency. Therefore, the structures with integrated wind turbines are unoccupied around the floors where they are placed.

But if we take a laypersons view, each blowing of wind causes the noise. Depending on its strength, the intensity of noise generated by hitting the objects that get in his way (buildings, trees, etc.). Many tests were conducted on the impact of wind noise on human health. By analyzing available data on the hazards of noise from wind turbines, it leads to the conclusion that it does not pose a potential hazard to human health. If there are problems, they are on a personal level of each individual and are not applicable to the general conclusion that the noise from wind turbines is harmful [3].

After construction of the building shown in the picture, architects started the idea of designing buildings that will have the equipment to produce energy from renewable sources for their own use. The most known is Zero Energy Tower (Fig. 5) which is planned to be built in China. His investors (Guangdong Tobacco Company) decided to build sustainable energy skyscrapers, and for this task they have employed reputable company which designs such buildings, Skidmore, Owings \& Merrill LLP [4].

The company has made a concept that wind will flow through the structure of the building and run wind turbines. And, also, solar cells will be mounted on 


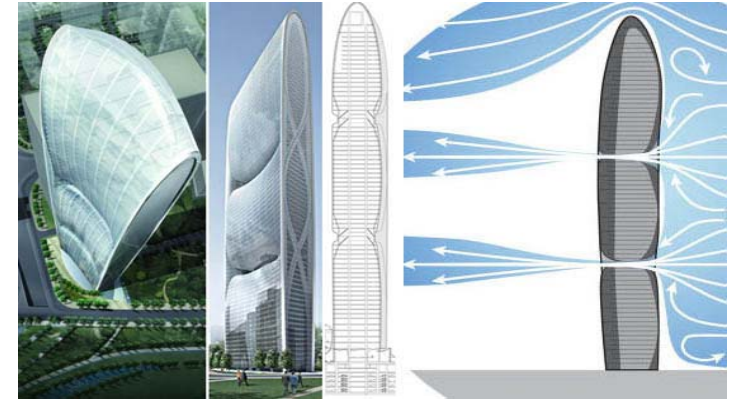

Fig. 5 Guangdong Tobacco Tower in China.

the facade of the building. The building is still being built and we are waiting for the first feedback on the energy independence of the skyscraper.

With the construction of the Bahrain WTC and Zero Energy Tower, architects started the era of designing skyscrapers that necessity for energy settle down from their own resources. The latest among them is the skyscraper project called "Castle House" or "Strata SE1" [5] in London (Figs. 6-7).

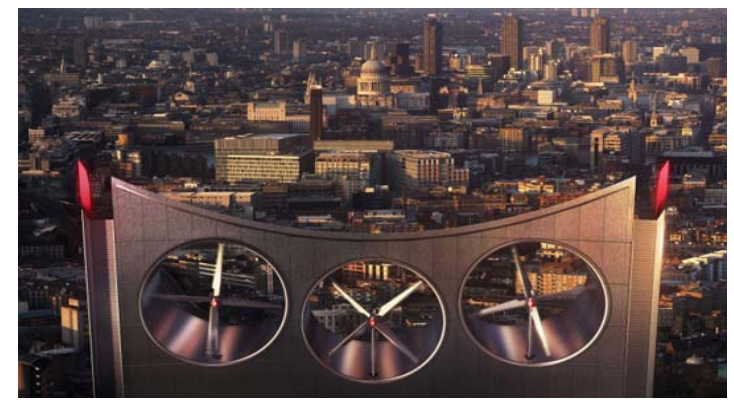

Fig. 6 Detail of the Castle House.

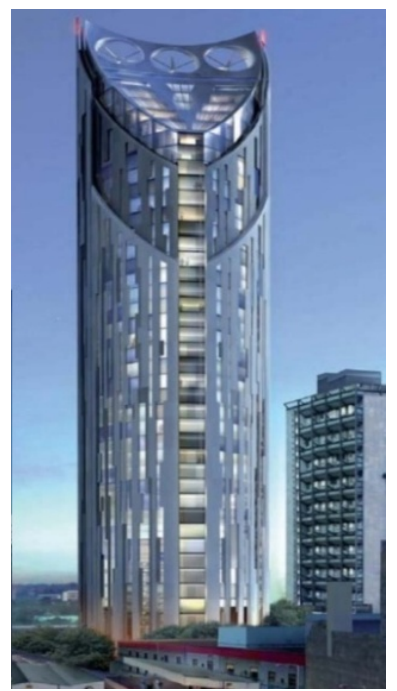

Fig. 7 The Castle House, Elephant and Castle in Southwark, London.
For some time now, the debate is run about cost effectiveness and efficiency of such structures, which in its structure has three integrated wind turbines, which should produce electricity for lighting and ventilation.

Besides the skyscrapers in the megalopolises, wind turbines are increasingly being put to great sporting facilities. This may be because a great necessity for energy is needed by such stadiums, and there is a large amount of people who visit them. In this way, running costs are reduced, but it, also, educates people and rises up awareness about renewable energy. But there are potential hazards that wind turbines represent.

An example of this is a football club Manchester City [6] that requested permission to set up wind turbines in the stadium in 2006, but due to security reasons (ice on the blades and the threat of it), the request was refused. The opposite example of this is the stadium of the University of North Texas (UNT) [7] that supports wind turbines and will provide about $6 \%$ of necessary energy. Soon, other universities and sports clubs across the United States submitted requests for placing wind turbines on their stadiums, such as a baseball stadium Cleveland State University (CSU), "The Lincoln Financial Field", in Philadelphia (Figs. 8-9), a football stadium "The Riverside Stadium" in Middleborough in North Yorkshire, England.

Besides the integration of wind turbines on buildings and sports facilities, planners and architects are considering more options. Thus, recently are appearing the concepts of installing wind turbines on the roads and bridges. Also, students at Arizona University [8] proposed a set of horizontal wind turbines above the highway that will be run by wind turbulence from the vehicles (Fig. 10). Each of the turbines by the assessment should produce about 9600 $\mathrm{kWh}$ of electricity annually and distribute it in the power grid. In addition to this concept, there is an idea of installing wind turbines in the construction of bridges and viaducts. One of such concepts is planned for the bridge between Italy and Scilla Bagnera (Fig. 
11) [9].

Looking at the idea of installing new wind turbines in all possible structures for sustainability and energy independence, it is impossible to ignore all the problems that accompany them. In addition to the long payback period and the noise, buildings integrated wind turbines are criticized for the threat that blades potentially represents on the environment [10].

Since the blades are sometimes 30 feet long, fall down from tens of meters high, in case some of the mounting security system fails, it potentially threatens all buildings, roads and passersby in a radius of several hundred meters. So far, there was no recorded case (or at least the producers and owners do not want them to go public with this information, if any of such

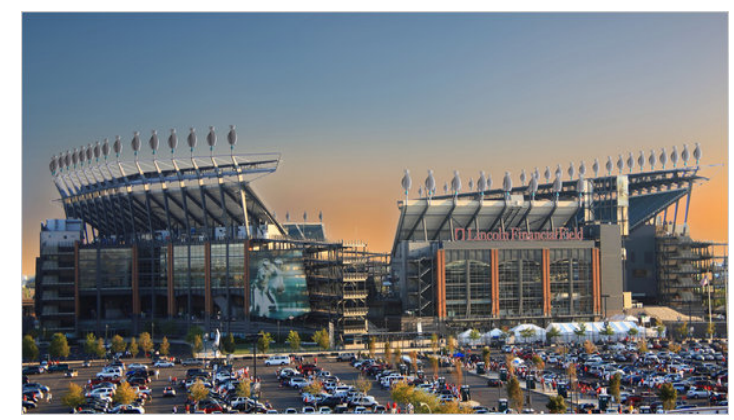

Fig. 8 Lincoln Financial Field, Philadelphia.

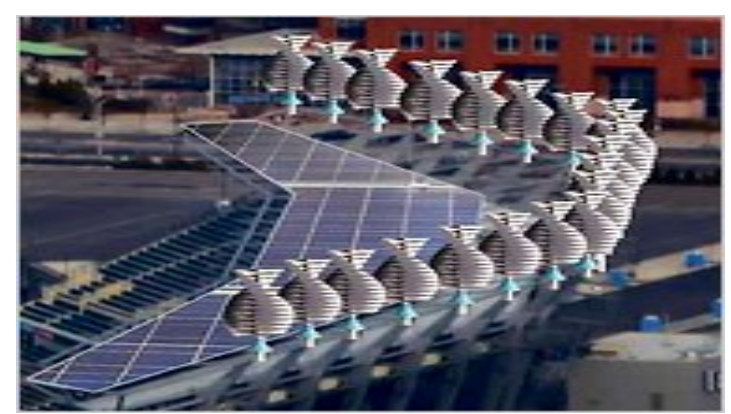

Fig. 9 Detail of Lincoln Financial Field.

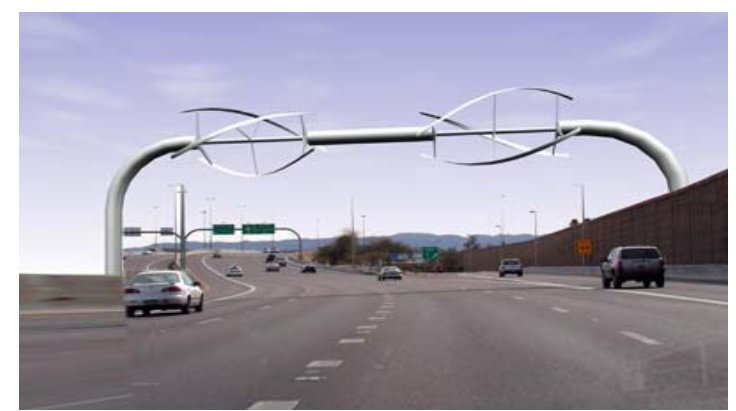

Fig. 10 Horizontal wind turbines on the highway.

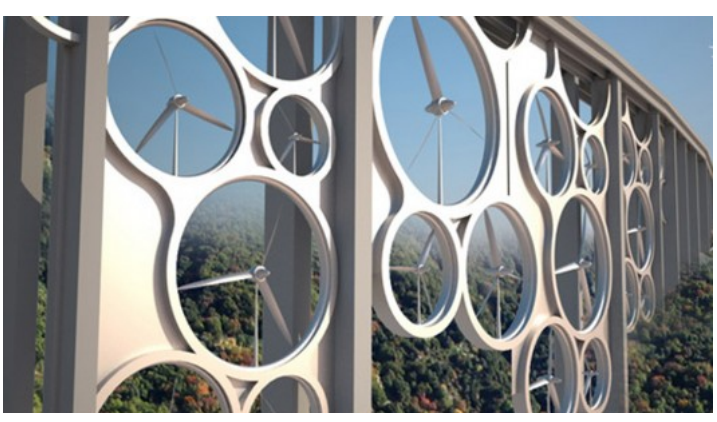

Fig. 11 Wind turbine in bridge, Bagnera Scilla in Italy.

cases), but there is always a potential danger.

And the fourth and the biggest problem is the fact that the rotation of the blade comes to creating vibrations [3]. The vibrations are transmitted on the building and its construction and are creating an additional burden. Many designers of these buildings discuss about this problem and how to solve it, by proposing different forms of wind turbines and their positions, but the problem still remains. The general conclusion remains that the design of buildings with turbines mounted has to reckon with stress of vibration. If they do not pay attention to that while designing the building, it can lead to structural stress as similar to earthquake and destruction of building [11].

With the development of new technologies and materials on the market, today we can find a large number of wind turbines, which are produced from different materials. Increasingly, the market can find a wind turbine with blades made from carbon fiber and fiberglass, which when compared to those made of different aluminum alloys are a lot easier, more flexible, quieter, safer, and more expensive.

Each of the manufacturers for their wind turbines (independently mounted on the building) say that they have a certain efficiency that sounds nice on paper. But when you start to measure the amount of energy produced, these results are dramatically falling, and it raises the question of feasibility of investment in wind turbines as an independent power producers. If we look at wind turbines integrated with the building (BAWT and HAWT), except for a small amount of energy produced, we will find expensive calculations 
that require numerous calculations for long-term performance and testing models. When such studies have the results that will justify our return on investment, the question still remains whether this will indeed be the same in the field. Because, conditions in the lab far from the conditions on the ground. Such turbines are typically combined with another renewable energy source.

Very often we can encounter wind turbines placed for advertising purposes to show how companies are environmentally conscious or to attract attention of passersby to think about renewable energy. Thus, in Florida, all along the highway, the advertisements with turbines have been installed in order to encourage thinking about wind turbines (Fig. 12). But on the other hand looking at the reviews of the environment, i.e., the passersby, the most common comment is that most of the time the blades are not spinning, and their conclusion is that it might not work at all.

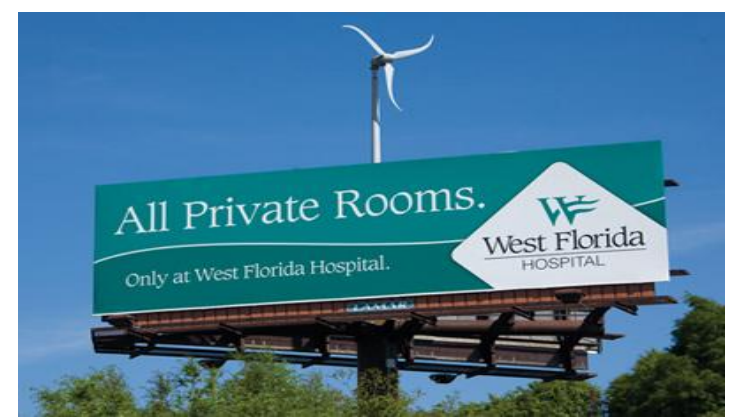

Fig. 12 The commercial wind turbine, Florida.

\section{Conclusions}

Wind turbines for the built environment that exploit higher wind speeds around buildings have to be designed for different types of flow. Considering the necessary modifications of the building to encourage good flow properties for the wind turbine, the most attractive option is to place the turbines on top of or alongside a building. Due to different wind conditions, like lower average wind speed and higher turbulence intensity, compared to the wind on-shore and off-shore, a vertical axis wind turbine might be preferable for roof.
Besides the skyscrapers in the megalopolises, wind turbines are increasingly being put to great sporting facilities. In this way, running costs are reduced, but it, also, educates people and rises up awareness about renewable energy.

Looking at the idea of installing wind turbines in urban environment, it is impossible to ignore all the problems that accompany them. In addition to the long payback period, noise and vibration, wind turbines integrated in the buildings are criticized for the threat that blades potentially represents on the environment.

\section{References}

[1] World's first building-integrated wind turbines, http://www.treehugger.com/renewable-energy/worlds-firs t-building-integrated-wind-turbines.html.

[2] Does building-integrated wind power work?, http://www.treehugger.com/renewable-energy/does-build ing-integrated-wind-power-work.html.

[3] W. David Colby, et al., Wind turbine sound and health effects: An expert panel review, American Wind Energy Association and Canadian Wind Energy Association, December 2009, http://www.awea.org/learnabout/publica tions/upload/awea_and_canwea_sound_white_paper.pdf.

[4] http://www.som.com/content.cfm/www_projects?sort_by $=\mathrm{FW}$.

[5] Strata SE1 on Wikipedia, http://en.wikipedia.org/wiki/Strata_SE1.

[6] City of Manchester Stadium on Wikipedia, http://en.wikipedia.org/wiki/City_of_Manchester_Stadiu $\mathrm{m}$.

[7] HKS designs wind turbines to generate power for new UNT football stadium, Enhanced Online News, http://eon.businesswire.com/news/eon/20110411007066/ en/HKS-Sports-\%26-Entertainment-Group/wind-turbine/ University-of-North-Texas.

[8] Highway wind turbines to capture energy from passing vehicles, Green Car News, http://green.autoblog.com/2007/05/01/highway-wind-turb ines-to-capture-energy-from-passing-vehicles/.

[9] Building a bridge to renewable energy, http://www.gizma g.com/solar-wind-bridge-concept/17771/.

[10] The folly of building-integrated wind, http://www.buildinggreen.com/auth/article.cfm/2009/4/29 /The-Folly-of-Building-Integrated-Wind.

[11] A. Wilson, Project: Folly of building-integrated wind, Environmental Building News, http://www.solaripedia.com/13/93/folly_of_building-inte grated_wind.html. 